\title{
Does chroma on the line increase attention to the line in pigeons?*
}

\author{
THEODORE T. HIROTA, VIRGINIA K. MILAM, and DENNIS W. FERENC \\ University of Windsor, Windsor, Ontario, Canada N9B3P4
}

\begin{abstract}
Two groups of pigeons received differential discrimination training on the presence vs absence of a vertical line on a white surround. The line was green for one group and black for a second group. Generalization tests along the angularity dimension showed that both green and black lines produced equally steep gradients. The results suggested that the addition of chroma to the line does not increase attention to the line.
\end{abstract}

Newman and Baron (1965) observed stimulus control along the angularity dimension in the form of steep generalization gradients following differential training on the presence (S+) and absence ( $\mathbf{S}-$ ) of a white vertical line on a green surround. Stimulus control was absent (i.e., a flat gradient appeared) when a red surround replaced the green surround as $\mathbf{S}-$. Newman and Baron (1965) and Baron (1965) proposed that pigeons may attend selectively to one stimulus dimension (in this case, color) rather than another (line orientation). If color is a more salient dimension than line orientation, would attention to the line be more enhanced if the line were chromatic (on a white surround) than if the line were white (on a chromatic surround)? Baron and Vacek (1967) explored this possibility using two groups of pigeons and obtained a steep gradient for the group trained with the chromatic line. The group trained with the white line produced a flat gradient. Baron and Vacek's results were consistent with the hypothesis that the chromatic line increased attention to the angularity dimension. However, Baron and Bresnahan (1969) pointed out that Baron and Vacek's results were open to two interpretations, namely, that the chroma of the line may have increased attention to the line or that the chroma of the surround may have decreased attention to the line. The second alternative was examined by Baron and Bresnahan (1969) using presence vs absence of a white vertical line with green surrounds for one group and black surrounds for a second group. Steeper gradients were obtained with the black surround, suggesting that the green surround decreased attention to the white line. However, the effect was relatively weak since the results were not significant when analyzed apart from two other groups given nondifferential (S+ only) training on the vertical line.

The present experiment was designed to investigate the first interpretation using a control condition comparable to the Baron and Bresnahan (1969) study. If

\footnotetext{
*This paper is based in part upon a thesis submitted by the second author in partial fulfillment of the requirements for the MA degree at the University of Windsor, 1972.
}

the addition of chroma to the line enhances attention to the line, then a control group with chroma absent from the line should show less attention to the line. Two groups were trained with a vertical line as $S+$ and a white surround as $\mathrm{S}-$. For one group the line was green, and for the other group it was black.

\section{METHOD}

\section{Subjects and Apparatus}

Twenty experimentally naive male White $\mathrm{King}$ pigeons were maintained at approximately $75 \%$ of their free-feeding weights. Two standard Lehigh Valley experimental chambers (Model 1417) were used. In each chamber, the $10 \frac{1}{2}$-in.-high $x$ $91 / 2$-in.-wide rat panel was replaced by a panel containing a single 1-in.-diam key $83 / 4$ in. above the floor. A 2 -in.-square feeder opening was located 5 in. below the key. Each transparent response key could be transilluminated from behind by a standard in-line display unit with a 1/8-in.-wide line in five possible orientations from $60 \mathrm{deg}$ counterclockwise to $60 \mathrm{deg}$ clockwise from vertical $(0 \mathrm{deg})$ in $30-\mathrm{deg}$ steps. The lines were black on a white surround in one chamber and green on a white surround in the second chamber. The green line was produced by switching on a display light source for a Kodak Wratten filter (No. 13) $(537 \mathrm{~nm})$. A feeder light replaced the houselight and keylight during 4-sec presentations of a grain mixture.

\section{Procedure}

The Ss were run in two replications of 10 birds each. On Day 1, Ss were assigned randomly to either an experimental (E) or control (C) group and adapted to the appropriate experimental chamber. On Days 2 and 3 , the $S s$ were magazine-trained and auto-shaped (see Brown \& Jenkins, 1968) to peck a green or black vertical line. On Day 4, all Ss were reinforced on a 30-sec variable-interval schedule. Sessions were terminated on Days 2, 3, and 4 after 50 reinforcers.

Differential discrimination training began on Day 5 and continued through Day 14. Thirty-two 55 -sec periods of $\mathrm{S}+$, each containing two randomly interspersed reinforcers, were alternated with $3215-\mathrm{sec}$ periods of $\mathrm{S}-$ in an ABBA BAAB sequence. The $S+$ and $S-$ periods were separated by brief $(0.40-\mathrm{sec})$ blackouts. For Group $E$, the $S+$ was a green vertical line on a white surround and the $S$ - was a white surround. For Group $C$, the $S+$ was a black vertical line on a white surround and the $S$ - was a white surround.

On each of Days 15 and 16, all Ss received a warm-up period followed immediately by a generalization test. The warm-up period contained six 45 -sec presentations each of $S+$ and $S-$ in a random sequence with two interspersed reinforcers during each 


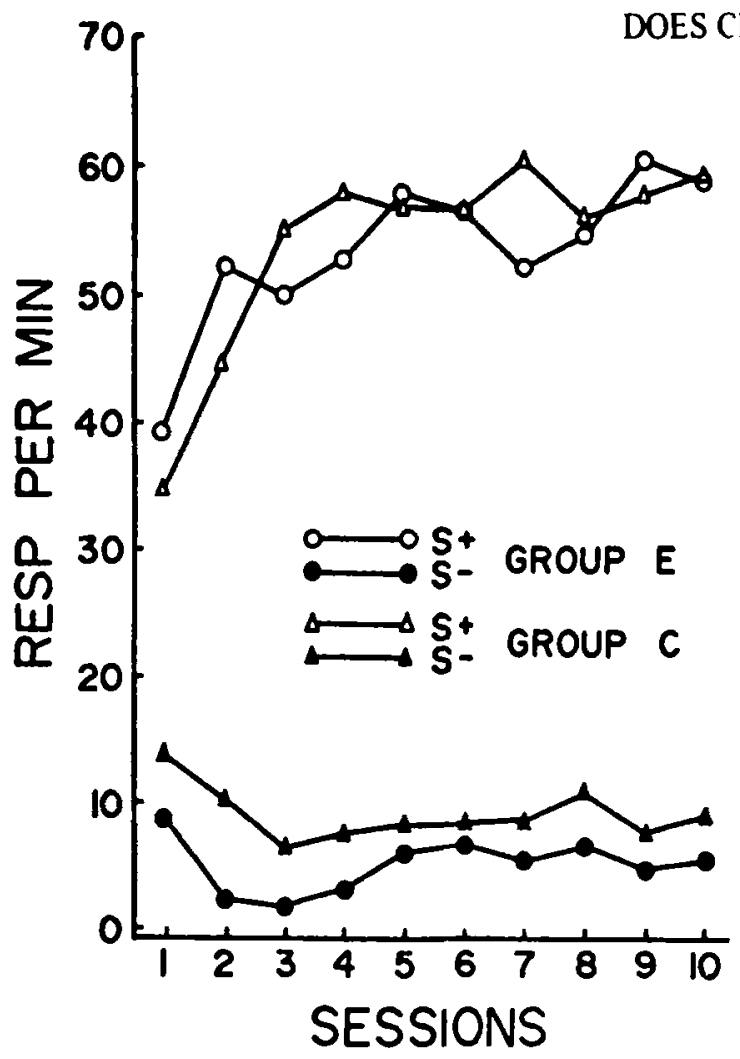

Fig. 1. Mean response rates to $S+$ and $S-$ by Groups $E$ and $C$ during discrimination training.

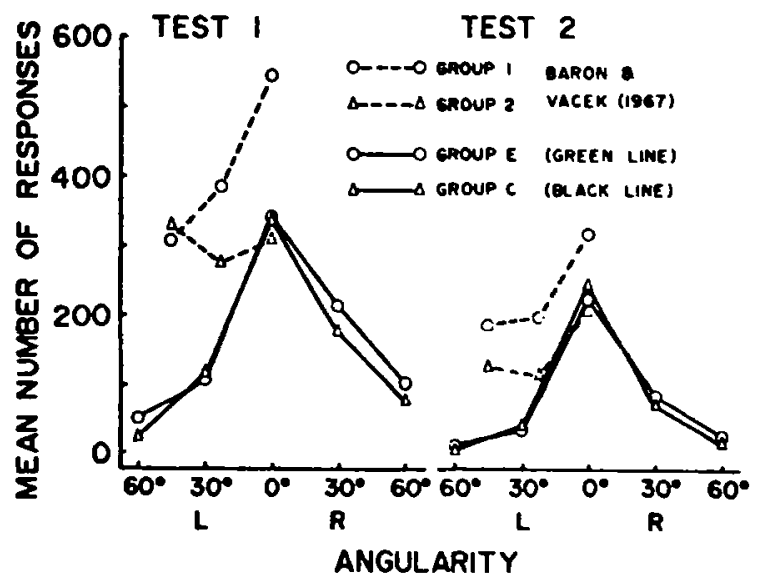

Fig. 2. Mean absolute number of responses to each test stimulus for Groups $E$ and $C$ on each test day. Dashed lines indicate replotted data from a study by Baron and Vacek (1967).

St presentation. The generalization test consisted of 10 presentations each of five line orientations (including $S+$ ) for 45 -sec periods in a counterbalanced order. All lines were green for Group $E$ and black for Group $C$ during each test. Successive presentations of test stimuli were separated by $0.40-\mathrm{sec}$ blackouts. No reinforcers were provided during testing.

\section{RESULTS AND DISCUSSION}

Figure 1 presents the mean response rates to $S+$ and
S- by Groups $\mathbf{E}$ and $\mathbf{C}$ during discrimination training. $\mathbf{A}$ three-way analysis of variance with repeated measures on two factors yielded a significant main effect of S+ vs S$(F=112.15, \mathrm{df}=1 / 18, \mathrm{p}<.01)$ but not for groups $(F<1)$ or days $(F<1)$. The interactions of Groups by S+ vs $S-(F<1)$ and Groups by $S+$ vs $S-$ by Days $(F<1)$ were not significant and indicated that the discrimination performance by the two groups was comparable. Figure 2 shows the absolute generalization gradients for Groups $\mathrm{E}$ and $\mathrm{C}$ on the 2 test days. A separate two-way analysis of variance with repeated measures on one factor was performed on responses to the left of S+ (including S+) on each of the 2 test days. Neither the groups effect nor the Groups by Angular Orientation interaction was significant $(F<1)$ on either test day. Separate analysis of variance on responses to the right of $S+$ (including $S+$ ) also indicated no significant differences in gradient slopes. The similarity in gradient slopes for Groups $E$ and $C$ suggests that the removal of chroma from the line does not decrease attention to the line. Baron and Vacek's (1967) results, reported as total number of responses by each group, were replotted as means and are shown in Fig. 2 for purposes of comparison. While Baron and Vacek's Group 1 (trained on the presence vs absence of a green line) indicates a higher overall level of responding as compared to Group E, the gradient slopes for these two groups appear similar on both test days.

The attention-increasing effect of chroma on the line reported by Baron and Vacek was inferred from the difference in slopes between Groups 1 and 2 on Test 1 . Differential training on the presence vs absence of a white line on a green surround (Group 2) generally produces steep gradients (Newman \& Baron, 1965; Newman \& Benefield, 1968; Baron \& Bresnahan, 1969). A possible explanation for the flat gradient obtained by Baron and Vacek, but not by the others, lies in a procedural difference during testing. Baron and Vacek simultaneously varied line orientation and wavelength during the generalization tests. Variations in the color of the surround during testing may have masked control by the angularity dimension and produced the flat gradient in Group 2. This interpretation is consistent with the masking effect reported by Thomas, Svinicki, and Svinicki (1970).

\section{REFERENCES}

Baron, M. R. The stimulus, stimulus control, and stimulus generalization. In D. I. Mostofsky (Ed.), Stimulus generalization. Stanford, Calif: Stanford University Press. 1965.

Baron, M. R., \& Bresnahan, E. L. The effect of chromatic surround upon generalization along an angularity dimension in pigeons. Psychonomic Science, 1969, 15, 9-10.

Baron, M. R., \& Vacek, C. T. Generalization gradients along wavelength and angularity dimensions in pigeons following two differential training procedures. Psychonomic Science. $1967.9,423-424$.

Brown. P. L.. \& Jenkins, H. M. Auto-shaping of the pigeon's 
key-peck. Journal of the Experimental Analysis of Behavior, $1968,11,1-8$.

Newman, F. L., \& Baron, M. R. Stimulus generalization along the dimension of angularity: A comparison of training procedures. Journal of Comparative \& Physiological Psvchology; 1965, 60, 59-63.

Newman, F. L., \& Benefield, R. L. Stimulus control, cue utilization, and attention: Effects of discrimination training.
Journal of Comparative \& Phỵsiological Psychology, 1968, 66 , $101-104$.

Thomas. D. R.. Svinicki, M. D., \& Svinicki, J. G. Masking of stimulus control during generalization testing. Journal of Experimental Psychology, 1970, 84, 479-482.

(Received for publication June 12, 1972; revision received January $22,1973$. ) 